LWSA

PAPER - OPEN ACCESS

\title{
Globalisasi, Transformasi Budaya Akademik dan Masa Depan Universitas Sumatera Utara
}

\author{
Author $\quad$ : Fernanda Adela Putra \\ DOI $\quad: 10.32734 /$ lwsa.v1i2.210 \\ Electronic ISSN : 2654-7066 \\ Print ISSN : 2654-7058
}

Volume 1 Issue 2 - 2018 TALENTA Conference Series: Local Wisdom, Social and Arts

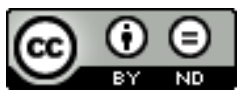

This work is licensed under a Creative Commons Attribution-NoDerivatives 4.0 International License.

Published under licence by TALENTA Publisher, Universitas Sumatera Utara
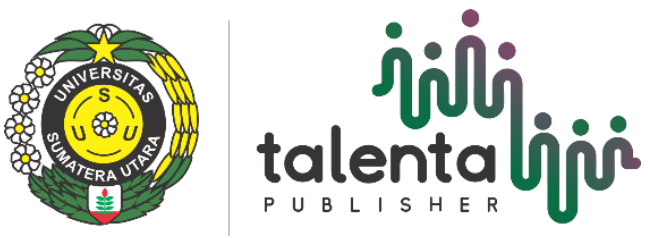


\title{
Globalisasi, Transformasi Budaya Akademik dan Masa Depan Universitas Sumatera Utara
}

\author{
Fernanda Adela Putra, S.Sos, MA ${ }^{\mathrm{a}}$
}

\begin{abstract}
Salah satu tantangan utama yang dihadapi oleh perguruan tinggi di dunia termasuk Indonesia adalah kemampuan universitas menghadapi arus globalisasi. Universitas Sumatera Utara (USU) memiliki tanggung jawab secara moral dan akademis untuk merespon globalisasi yang merupakan peluang sekaligus tantangan agar mendapat kepercayaan dari industri tenaga kerja, pemerintah dan masyarakat. Penelitian merupakan penelitian kualitatif dengan paradigma kritis. Hasil dari penelitian ini bahwa dalam rangka menuju akreditas unggul dan pengakuan internasional harus melakukan transformasi budaya akademik, perguruan tinggi di era digital dan perbaikan tata kelola untuk peningkatan daya saing. Kesimpulannya Universitas Sumatera Utara (USU) berbenah diri secara kelembagaan dan dipandang sebagai perguruan tinggi berbasis penelitian, sehingga membuka ruang ruang untuk melakukan kemitraan dengan berbagai institusi baik nasional dan internasional dalam proses penelitian.
\end{abstract}

Kata Kunci : Globalisasi; budaya akademik; transformasi akademik

\section{Pendahuluan}

Secara global ada konsensus yang berkembang di kalangan pembuat kebijakan dan pelaku usaha industri bahwa universitas merupakan pendorong penting bagi pertumbuhan ekonomi dan pembangunan. Sebab, secara langsung perguruan tinggai berkontribusi pada terciptanya orang yang terampil, kompeten, dan menghasilkan hal baru dalam menciptakan inovasi menunjang ekonomi nasional kompetitif yang menghasilkan dan mentransfer pengetahuan.

Kearney (2013) dalam jurnal yang ditulis oleh Olsson and Cooke dalam "The evolving path for strengthening research and innovation policy fsor development": “Universitas yang berbasi riset unggulan penting untuk negaranegara industri untuk mendominasi peringkat global. Sebaliknya, bagi negara yang basis penelitiannya rendah dituntut untuk melakukan pengembangan pengetahuan lokal (local wisdom) dari sistem akademis mereka. Sistem ini digunakan untuk memenuhi kebutuhan dalam negeri untuk memelihara jaringan perkembangan pengetahuan global"

Globalisasi merupakan kekuatan besar yang amat mempengaruhi dunia penguruan tinggi Indonesia. Kalau lembaga pendidikan tinggi nasional tidak mampu merespons tantangan globalisasi ini dengan memadai, diperkirakan lembaga tersebut akan tidak mampu mempertahankan eksistensinya di masyarakat dan secara pelan tetapi pasti akan kehilanganan peranannya. Mudah-mudahan ramalan yang pesimistis ini tidak perlu terjadi asal kita mampu mengembangkan strategi-strategi survival yang tepat.

Lebih lanjut, saat ini dunia perguruan tinggi yang menganut paham universialisme ilmu pengetahuan dan teknologi sebenarnya selalu memperhatikan dan memperhatikan pertimbangan bahwa masyarakat pendidikan Indonesia adalah bagian dari masyarakat global. 
Globalisasi yang menyentuh semua aspek baik ekonomi, sosial, politik dan budaya secara cepat mengalami dinamikan hingga menjadi sebuah peluang sekaligus tantangan bagi seluruh perguruan tinggi di Indonesia termasuk Universitas Sumatera Utara (USU).

Tulisan ini merupakan refleksi saya yang juga merupakan alumni USU dan saat ini menjadi pengajar di USU. Saya merasakan perubahan begitu cepat seiring dengan perkembangan zaman. Jika pada saat saya mahasiswa pengisian KRS masih menggunakan mesin tik, informasi terkait jadwal mata kuliah, dan informasi nilai masih manual. Saat ini, sudah bisa dilihat secara online di internet tanpa harus pergi melihatnya ke kampus.

Lebih lanjut terkait informasi jurnal penelitian, pada saat saya mahasiswa hanya tersedia di perpustakaan dan ruangruang tertentu di fakultas. Saat ini, sudah bisa diakses secara bebas karena sudah tersaji secara online di internet baik itu jurnal lokal, jurnal nasional dan jurnal internasional.

Bahkan yang paling mutakhir saat ini dosen sudah dituntut harus mampu mempublikasi jurnal nasional terakreditasi atau jurnal internasional bereputasi yang terindeks di Scopus atau Thomson Reuters. Selanjutnya,publikasi ini kemudian menjadi salah satu indikator dosen untuk naik golongan kepangkatan. Lebih luas lagi, untuk departemen, fakultas dan universitas menjadi salah satu alat ukur dalam menentukan nilai akreditasi. Pada bagian ini secara kinerja USU harus menaikkan standardnya terkait tridarma perguruan tinggi seperti pengajaran, penelitian dan pengabdian kepada masyarakat.

Sebagai lembaga perguruan tinggi, Universitas Sumatera Utara memiliki tanggung jawab moral mengembangkan ilmu pengetahuan dan teknologi. Sebab saat ini, USU adalah lembaga yang paling merasakan tuntutan sosial untuk perubahan global tersebut. Industri usaha, pemerintah dan masyarakat yang memerlukan ilmu pengetahuan baru yang berbasis teknologi informasi, rekaya sosial, bioteknologi serta ilmu-ilmu multidisiplin lainnya akan menuntut USU harus memenuhi kebutuhan mereka akan ilmu pengetahuan dan teknologi dengan standard yang lebih tinggi.

Informasi paling baru terkait tanggungjawab moral ini adalah kebijakan pemerintah pusat menurut Peraturan Pemerintah Republik Indonesia Nomor 11 Tahun 2017 Tentang Manajemen Pegawai Negeri Sipil terkait sarjana (S1) dan magister (S2) seluruh perguruan tinggi yang lulus dengan nilai cumlaude, program studi akreditas A dan Universitas akreditasi A diberi affirmasi saat mengikuti ujian Calon Pegawai Negeri Sipil (CPNS). Pada syarat ini, banyak alumni USU yang tidak bisa mengikutinya karena terkendala karena akreditas universitas yang masih B.

Artinya perubahan yang disebabkan oleh globalisasi ini harus direspons dengan baik oleh USU agar dapat tetap memainkan peranan pentingnya dalam mendapatkan kepercayaan pemerintah, masyarakat dan industri usaha baik di Indonesia bahkan internasional. Sebab, ini tidak hanya menyangkut masalah pembiayaan pemerintah untuk USU akan ditekan, perubahan populasi calon mahasiswa yang akan dikurangi dan otonomi kampus juga terancam ketika USU tidak lagi menjadi universitas favorite calon mahasiswa karena kesulitan dalam mengakses pekerjaan.

Sebab, untuk menjadi perguruan yang unggul USU harus melakukan sebuah transformasi budaya akademik. USU harus cermat mersepon arus globalisasi yang sedang terjadi dan memenuhi permintaan masyarakat tersebut. Ketika USU tidak cepat tanggap karena jelimetnya birokrasi kampus, rendahnya jumlah publikasi ilmiah, budaya akademik yang kaku, penjaminan mutu dan pencapaian target atas standard yang telah ditentukan. Kekhawatiran utama adalah para lulusan USU tidak lagi menjadi pilihan utama pada sebuah angkatan kerja di generasi mendatang.

Oleh karena itu, berdasarkan pemaparan diatas, maka saya menulis jurnal yang berjudul: "Globalisasi, Transformasi Budaya Akademik dan Masa Depan Universitas Sumatera Utara" dalam merespon tantangan USU kedepannya untuk menjadi universitas unggul dan pengakuan internasional juga nasional.

\section{Metode penelitian}

Penelitian merupakan penelitian kualitiatif dengan analisis kritis dalam merespon femenomena sosial. Peneliti mengumpulkan data melalui jurnal internasional, jurnal nasional, sebagai data primer. Kemudian, dokumen-dokumen yang berasal dari Univeritas-universitas di baik Internasional dan nasional yang memiliki akreditas unggul sebagai data sekunder. Penghimpunan data penelitian juga dilakukan melalui proses penelaahan terhadap dokumen-dokumen ataupun laporan yang berkaitan dengan fokus tulisan. Laporan yang ditelaah akan melalui proses mendapatkan persetujuan dari pihak yang berwenang di lokasi penelitian di Universitas Sumatera Utara. 


\section{Hasil dan pembahasan}

\subsection{Transformasi budaya akademik}

Paradigma sebuah perguruan tinggi bisa dilihat dari bagaimana caranya dalam mengembangkan visi dan misi universitas. Universitas Sumatera Utara (USU) memiliki visi; "Menjadi perguruan tinggi yang memiliki keunggulan akademik sebagai barometer kemajuan ilmu pengetahuan yang mampu bersaing dalam tataran dunia global". Berdasarkan visi tersebut sebenarnya sejak awal USU sudah menyadari bahwa tantangan utama perguruan tinggi saat ini adalah globalisasi. Namun, pengembangan sebuah visi perlu disertai komitmen dalam mencapai apa yang menjadi target yang sudah ditentukan sejak awal.

Apalagi sejak tahun 2003, USU berubah status dari suatu Perguruan Tinggi Negeri (PTN) menjadi suatu perguruan tinggi Badan Hukum Milik Negara (BHMN). Perubahan status USU dari PTN menjadi BHMN merupakan yang kelima di Indonesia yang membuat USU menjadi perguruan tinggi yang otonom dalam mengelola lembaga, mengelola keuangan dan kebijakan.

Penyelenggaraan pendidikan tinggi USU yang berbasis otonomi kampus. Sejatinya yang menjadi wadah bagi pengembangan karakter sumber daya manusia mahasiwa USU yang didasarkan pada pemberdayaan yang mengandung semangat demokratisasi pendidikan yang mengakui kemajemukan dengan orientasi pendidikan yang menekankan pada aspek pencarian alternatif penyelesaian masalah aktual berlandaskan kajian ilmiah, moral, dan hati nurani.

Selanjutnya USU harus pula melakukan trasformasi budaya akademik dalam mengahadapi globalisasi dengan tuntutan harus mampu menghasilkan lulusan yang menjadi pelaku perubahan sebagai kekuatan modernisasi dalam kehidupan masyarakat luas yang lebih baik.

Hal ini sejalan dengan misi USU yang menyebutkan 3 poin penting:

1. Menyelenggarakan pendidikan tinggi berbasis otonomi yang menjadi wadah bagi pengembangan karakter dan profesionalisme sumber daya manusia yang didasarkan pada pemberdayaan yang mengandung semangat demokratisasi pendidikan yang mengakui kemajemukan dengan orientasi pendidikan yang menekankan pada aspek pencarian alternatif penyelesaian masalah aktual berlandaskan kajian ilmiah, moral, dan hati nurani;

2. Menghasilkan lulusan yang menjadi pelaku perubahan sebagai kekuatan modernisasi dalam kehidupan masyarakat luas, yang memiliki kompetensi keilmuan, relevansi dan daya saing yang kuat, serta berperilaku kecendikiawanan yang beretika; dan

3. Melaksanakan, mengembangkan, dan meningkatkan pendidikan, budaya penelitian dan program pengabdian masyarakat dalam rangka peningkatan kualitas akademik dengan mengembangkan ilmu yang unggul, yang bermanfaat bagi perubahan kehidupan masyarakat luas yang lebih baik.

Secara konsep, visi USU ini sudah sangat relevan dalam menyentuh dan menghadapi globalisasi. Namun, poin yang kurang adalah dalam proses-proses empirik para dosen harus menghadapi mahasiswa yang secara kultur yang berbeda dengan mahasiswa yang dihadapinya sebelumnya yang sifatnya hanya sekadar formalitas dalam proses pengembangan keilmuan seperti dengan gaya pengajaran monolog di depan kelas.

Tentu dalam rangka pengembangan ilmu pengetahuan butuh komitmen yang luas terhadap proses pengajaran, penelitian dan pengabdian kepada masyarakat yang sifatnya dialog (dua arah) dilakukan dengan serius dengan standart pengendalian mutu yang baik pula. Bukan tanpa alasan, hal ini bertujuan agar USU dapat mengukur seberapa jauh proses independesi penerimaan mahasiswa, proses pembelajaran dan proses mempersiapkan alumni yang dapat diterima pemerintah, pelaku usaha dan masyarakat. Artinya dalam setiap penelitian dan pengajaran, sejatinya USU sudah melibatkan mahasiswa baik itu mahasiswa strata S1 (sarjana), mahasiswa strata S2 (magister) dan mahasiswa strata S3 (S3) sudah ikut terlibat langsung tidak hanya simbolis saja tetapi secara nyata berada dilapangan juga memahami bagaimana realitas yang sebenarnya.

\subsection{Perguruan tinggi di era digital}

Sejak media sosial tumbuh subur di berbagai belahan dunia termasuk Indonesia pada awal tahun 2000-an. Seperti ; Friendster (2002), Facebook (2004), MySpace 2006, Twitter (2007) hingga Path (2011). Praktis aktivitas kehidupan manusia bergeser ke dunia digital. Perkembangan secara cepat media sosial ini selanjutnya memunculkan istilah Netizen. Dimana kata Netizen berasal dari kata Net yang berarti internet dan Citizen yang berarti warga. Jika diartikan 
berarti warga internet atau para pengguna internet. Artinya Netizen adalah siapa saja yang mengakses dan menggunakan internet. Di era saat ini pemanfaatan internet melalui media sosial tidak hanya berkaitan dengan online shop dan promosi produk saja. Pemanfaatan media sosial sudah mengarah ke hal-hal yang bersifat sosial, ekonomi, dan politik.

Selanjutnya, perkembangan internet memasuki ruang-ruang kampus tanpa batas dan ruang. Pada posisi ini kehidupan universitas memasuki fase globalisasi lebih nyata terkait informasi, transformasi dan komunikais yang kehidupannya tidak bisa dilepaskan dari internet. Bisa dipastikan bahwa seluruh mahasiswa USU adalah pengguna internet.

Hal ini disebabkan aktifitas pengisian Kartu Rencana Studi (KRS), informasi nilai mahasiswa bahkan terkait pendaftaran untuk keperluan wisuda dilakukan menggunakan internet. Praktis secara otomastis aktivitas kehidupan mahasiswa USU ketika kuliah bergeser ke dunia digital. Selanjutnya, hal ini diimbangi pula dengan beberapa dosen yang menuntut mahasiwa mengirim tugas melalui e-mail tentu bisa dipastikan bahwa ada tradisi baru dalam dunia akademik yang tidak kita sadari menjadi peluang sekaligus ancaman.

Misalnya terkait tugas atau karya ilmiah mahasiswa kerap dibebaskan untuk mengutip sumber dari internet yang kadang diambil dari blog yang tidak terkonfirmasi sebagai sebuah kebenaran ilmiah dan berakibat fatal terhadap kualitas sebuah tulisan karena risikonya menyangkut keaslian dan kebenaran sebuah tulisan. Buku-buku yang sejatinya penting dimiliki mahasiswa kini hampir jarang kita lihat di bangku mahasiswa ketika mengikuti perkuliahan. Jika kita baca rentetan perjalanan arus globalisasi yang melanda kampus-kampus besar dunia dan indonesia termasuk USU. Bahwa, tranformasi zaman terkadang tidak diikuti oleh transformasi budaya akademis.

Terdapat ketimpangan yang nyata bahwa sejatinya universitas memiliki transformasi tersendiri justru tergerus oleh teknologi yang sifatnya negatif. Hal ini tidka hanya terjadi untuk mahasiswa Usu saja, namun para pengajar terkendala dalam proses penyesuaian yang seharusnya memiliki batas-batas kewajaran. Padahal Usu pada saat ini membutuhkan budaya akademik yang kritis dalam melihat masalah, kreatif dalam melahirkan ide tentunya lahir secara organik dari rahim naskah-naskah akademik dosen dan mahasiswa USU. Dengan demikian sifat para mahasiwa dan dosen dalam menganalisis permasalahan bisa secara objektif dalam konstruksi pengembangan kelembagaan USU.

Disinilah peran dari kelembagaan universitas melalui strukur Rektor, Majelis Wali Amanat, Dewan Guru Besar, Senat Akademik, Dekanat, Departemen/Prodi hingga Biro Kepegawaian untuk menyatukan pandangan tentang kontruksi berfikir dalam menghadapi tantangan utama universitas. Sebab, perubahan zaman adalah sebuah kepastian bagi para pemangku kepentingan (stakeholders) tersebut dalam menghadapi perkembangan yang dinamis.

Pilihan utama adalah para stakeholders membangun sebuah dialog dalam setiap tantangan yang dihadapi USU kedepannya. Mengedepankan dialog dengan bertatp muka langsung didalam meja rapat tentu lebih baik daripada hanya berinteraksi melalui grup-grup media sosial seperti Whatsaap (WA), facebook atau grup messenger lainnya. Transformasi budaya ini tentu diimbangi dengan sikap mau menerima kritik terkait penulisan ilmiah dalam proses penelitian atau dialog antara mahasiswa dan dosen diruang-ruang kelas. Pada bagian ini, output utamanya adalah penghargaan terhadap prestasi dan pengembangan yang tinggi terhadap tradisi ilmiah USU.

\subsection{Perbaikan tata kelola untuk peningkatan daya saing}

Persaingan global sejatinya tidak hanya dihadapi secara kompetitif jika sebuah universitas memiliki keunggulan komaparatif yang tidak dimiliki oleh perguruan tinggi lainnya. Keunggulan komparatif ini bisa saja basisnya prestasi mahasiswa atau dosen, riset unggul betaraf internasional atau menyangkut masalah proses seluruh kegiatan yang akuntabel, terbuka dan transparan.

Tata kelola dalam konteks perguruan tinggi, diartikan oleh Marginson dan Considine (2000) secara luas mencakup "Hubungan internal, hubungan eksternal atau bagian dari keduanya. Dengan demikian, tata kelola perguruan tinggi berhubungan dengan penentuan nilai di dalam universitas, sistem pengambilan keputusan mereka dan alokasi sumber daya misi dan tujuan, pola otoritas dan hirarki dan hubungan universitas sebagai institusi ke dunia akademis yang berbeda di dalamnya dan dunia pemerintahan, bisnis dan komunitas tanpa” 
Jika kita membaca kembali statuta perguruan tinggi. Kedudukan USU berbeda dengan kedudukan Perguruan Tinggi Swasa (PTS), dalam hal ini USU menjembatani kepentingan pemerintah sebagai penanggungjawab akhir penyelenggaraan pendidikan dengan kepentingan masyarakat sebagai warga yang berhak atas pendidikan yang layak.

Tantangan yang dihadapi oleh USU sebagai sebuah lembaga universitas adalah soal cara mempertahankan otonomi perguruan tinggi sekaligus menjaga kebebasan akademik sambil tetap mempertahankan prinsip-prinsip tata kelola yang baik dan akuntabilitas kepada pemerintah yang mendelegasikan penyelenggaraan pendidikan tinggi kepada mereka.

Disini yang harus disadari bahwa elemen utama dalam menjalankan tata kelola perguruan tinggi secara kelembagaan. Kelembagaan bisa berkaitan dengan tujuan perbaikan SDM, infrastuktur bangunan fisik kampus, laboratorium, perpustakaan, lab komputer dan lain-lain. Rekontuksi keuangan berkaitan dengan keterbukaan terhadap fiansial kampus dan Birokrasi berkaitan dengan proses pengurusan izin dan administrasi yang luarannya adalah peningkatan kualitas alumni USU.

\section{Simpulan}

Univesitas Sumatera Utara (USU) sejatinya harus merespon secara cepat fenomena derasnya arus globalisasi yang saat ini semakin hari semakin kuat. Pilihan tinggal bagaimana USU merekontruksi diri sebagai sebuah lembaga perguruan tinggi dalam mentransformasikan budaya akademik yang akuntabel, terbuka dan transparan. Lebih jauh lagi, kemampuan USU untuk bersikap menarik batas dan fokus menjalankan USU harus senantiasa menjalankan rekontruksi pada bidang-bidang yang sifatnya kelembagaan, keuangan, birokrasi dan kolaborasi dalam merespon kebutuhan pemerintah dan masyarakat.

Sebab, ujian tentang bagaimana USU membangun hubungan dengan pasar, industri tenaga kerja, pemerintah dan masyarakat dapat dilihat bagaimana USU kedepannya dipandang sebagai perguruan tinggi berbasis penelitian, sehingga membuka ruang ruang untuk melakukan kemitraan dalam proses penelitian.

Baik itu dengan universitas di tingkatan global, dengan universitas sekawasan, perusahaan mitra bahkan pemerintah daerah yang tentunya akan meningkatkan akreditasi USU tidak hanya baik secara nasional tapi juga menjadi tujuan kerjasama ditingkatan global. Lebih lanjut, tuntutan riset unggulan saat ini membutuhkan kebaruan (novelty) yang masih menjadi bagian terpenting dalam proses riset. Harapan kita terhadap masa depan USU kedepannya bidang lebih lebih signifikan dalam proses kehidupan masyarakat yang lebih demokratis dan berkeadilan. Gagasan-gagasan yang lahir dari rahim para peneliti USU sangat membantu bagaimana USU di masa yang akan datang menjadi universitas yang kuat secara kelembagaan dan bagus secara riset.

\section{Referensi}

[1] Marginson, dan Considine, M. (2000). The Enterprise University: Power, Governance and Reinvention in Australia, Cambridge: Cambridge University Press.

[2] Massen P. (2014). Conviction, fragmentation and confusion: Universities and science policy in a rapidly changing global context. In N Cloete, P Maassen, J Mouton and T Moja (eds) Knowledge production in South African universities. Dordrecht: Springer.

[3] Reed M. (2002). New managerialism, professional power, and organisational governance in UK universities: A review and assessment. In A Amaral, GA Jones and B Karseth (eds) Governing higher education: National perspectives on institutional governance. Dordrecht: Kluwer hal 163-186.

[4] Soetjipto, Ani, dkk. (2014). "Otonomi Dan Tata Kelola Perguruan Tinggi Negeri Studi KasusDi Universitas Indonesia, Universitas Negeri Jakarta, Dan Universitas Islam Negeri Syarif Hidayatullah, Jurnal Masyarakat \& Budaya, Volume 16 No. 2 Tahun 2014 hal.295.

[5] Olsson A \& Cooke N. (2013). The evolving path for strengthening research and innovation policy for development. Tersedia di: http://www.oecd.org/sti/The\%20Evolving\%20Path\%20for\%20Strengthening\%20Research\%20and\%20Innovation\%20Policy\%20for\%20De velopment-\%20Asa\%20Olsson\%20and\%20Natalie\%20Cooke.pdf [accessed 20 December 2013].

[6] Pandor N. (2011). Science and Technology Budget Vote Speech by Minister Naledi Pandor: Enhancing excellence in science and technology for development economic growth and a better life for all citizens. Tersedia di: http://www.pmg.org.za/briefing/20110524-science-technologyministersbudget-speech

Dokumen/Internet:

[1] Lihat paper Sofian Effendi, Pengelolaan Perguruan Tinggi Menghadapi Tantangan Global, Dipresentasikan pada Seminar Nasional Majelis Rektor Indonesia di Makassar, 31 Januari - 2 Februari 2003

[2] Lihat Peraturan Pemerintah Republik Indonesia Nomor 11 Tahun 2017 Tentang Manajemen Pegawai Negeri Sipil. 
[3] Visi, Misi, dan Tujuan http://www.usu.ac.id/en/visi-dan-misi.html diunduh tanggal 20 september 2017 pukul 01.00 wib.

[4] Lihat Visi, Misi, dan Tujuan http://www.usu.ac.id/id/visi-dan-misi.html diunduh tanggal 21 september 2017.

[5] Jawaban politik generasi Y https://geotimes.co.id/kolom/grace-natalie-dan-jawaban-politik-generasi-y/ diunduh tanggal 21 september 2017 pukul 12.00 wib 